\title{
Crescimento de pitaia vermelha com adubação orgânica e granulado bioclástico
}

\author{
Growth of red pitaya with organic fertilizer and calcified seaweed
}

\author{
Rodrigo Amato Moreira ${ }^{\mathrm{I}^{*}}$ José Darlan Ramos $^{\mathrm{I}}$ Virna Braga Marques $^{\mathrm{I}}$ Neimar Arcanjo de Araújo \\ Paulo César de Melo
}

\section{- NOTA -}

RESUMO

\begin{abstract}
Objetivou-se com o trabalho avaliar o crescimento de pitaia vermelha (Hylocereus undatus) submetida à adubação orgânica e à aplicação de granulado bioclástico. $O$ delineamento experimental foi em blocos casualizados com oito adubações: testemunha, esterco de curral, cama de frango, granulado bioclástico, esterco de curral + cama de frango, esterco de curral + granulado bioclástico, cama de frango + granulado bioclástico e esterco de curral + cama de frango + granulado bioclástico, aplicados a cada três meses, com três blocos, e a parcela experimental composta por quatro plantas. Não foram observadas diferenças significativas no comprimento e no número de cladódios principais. Houve diferença significativa no número de cladódios laterais retirados e de cladódios emitidos acima do suporte. A adubação com esterco de curral + cama de frango + granulado bioclástico favoreceu o crescimento de plantas de pitaia vermelha.
\end{abstract}

Palavras-chave: Hylocereus undatus, Lithothamnium, nutrição de plantas.

\section{ABSTRACT}

The objective of the study was to evaluate the growth of red pitaya (Hylocereus undatus) subjected to organic fertilization and calcified seaweed application. The experimental design was in randomized blocks with eight fertilization: control, cattle manure, chicken manure, calcified seaweed, cattle manure + chicken manure, cattle manure + calcified seaweed, chicken manure + calcified seaweed and cattle manure + chicken manure + calcified seaweed, applied every three months, with three replications and plot consisted of four plants. There were no significant differences in the length and in the number of central cladodes. There were significant differences in the number of side cladodes removed and in cladodes above the support. Fertilization with cattle manure + chicken manure + calcified seaweed favored the growth of red pitaya.

Key words: Hylocereus undatus, Lithothamnium, plant nutrition.

No Brasil, existem pequenas áreas de produção de pitaia (Hylocereus undatus), situadas principalmente no estado de São Paulo, localizadas na região de Catanduva. Entretanto, devido ao maior consumo de frutas exóticas e ao seu valor comercial, surgiu interesse por parte dos fruticultores no plantio e cultivo dessa frutífera. Na região Sudeste, a produção dos frutos ocorre durante os meses de dezembro a maio. A produtividade média anual é de 14 toneladas de fruto/ ha (BASTOS et al., 2006).

Nos últimos anos, a procura por fontes alternativas de nutrientes tem aumentado devido à elevação do preço dos fertilizantes minerais. O uso de adubos orgânicos melhora a agregação do solo, especialmente porque influencia a infiltração do solo e a capacidade de retenção de água, bem como a drenagem, aeração, temperatura e penetração de raízes (OLIVEIRA et al., 2009).

A utilização de granulados bioclásticos, constituídos por algas calcárias (Lithothamnium), aplicados junto à matéria orgânica é interessante, pois

'Departamento de Agricultura, Universidade Federal de Lavras (UFLA), CP 3037, 37200-000, Lavras, MG, Brasil. E-mail: amatomoreira@yahoo.com.br. *Autor para correspondência. 
aumenta a disponibilidade de nutrientes para as plantas, devido à correção do $\mathrm{pH}$ e à ativação do desenvolvimento de bactérias autotróficas, responsáveis pelo processo de nitrificação (DIAS, 2000).

A incorporação de $50 \mathrm{~g} \mathrm{~L}^{-1}$ de granulado bioclástico ao substrato promoveu aumento no sistema radicular e na parte aérea de mudas de tangerineira Cleópatra (CRUZ et al., 2008).

Diante do exposto, objetivou-se avaliar o crescimento de pitaia vermelha submetida à adubação orgânica e à aplicação de granulado bioclástico.

$\mathrm{O}$ experimento foi instalado no setor de Fruticultura da Universidade Federal de Lavras, MG. Foram utilizadas mudas de pitaia vermelha (Hylocereus undatus), de dez meses de idade, com quatro cladódios principais e $1,25 \mathrm{~cm}$ de altura, provenientes de estacas de plantas matrizes sadias. Essas mudas foram plantadas em junho de 2008, em covas de 50x50x50cm, no espaçamento de $3 \mathrm{~m} \times 3 \mathrm{~m}$. As covas foram adubadas com fósforo ( $300 \mathrm{~g}$ de superfosfato simples) e matéria orgânica (20 litros de esterco de curral bem curtido), antes do plantio.

O solo do local do experimento possuía as seguintes características na camada de 0 a $20 \mathrm{~cm}$ : $\mathrm{pH}=6,00 ; \mathrm{P}=8,5 \mathrm{mg} \mathrm{dm}^{-3} ; \mathrm{K}=136,0 \mathrm{mg} \mathrm{dm}^{-3} ; \mathrm{Ca}=3,0 \mathrm{Cmolc}$ $\mathrm{dm}^{-3} ; \mathrm{Mg}=0,5 \mathrm{Cmolc} \mathrm{dm}^{-3} ; \mathrm{Al}=0,1 \mathrm{Cmolc} \mathrm{dm}^{-3} ; \mathrm{H}^{-}$ $\mathrm{Al}=2,6 \mathrm{Cmolc} \mathrm{dm}^{-3} ; \mathrm{Sb}=3,6 \mathrm{Cmolc} \mathrm{dm}^{-3} ; \mathrm{t}=3,7 \mathrm{Cmolc} \mathrm{dm}^{-3}$; $\mathrm{T}=6,2 \mathrm{Cmolc} \mathrm{dm}^{-3} ; \mathrm{m}=3,0 \% ; \mathrm{V}=58,0 \% ; \mathrm{B}=0,20 \mathrm{mg} \mathrm{dm}^{-3}$; $\mathrm{Zn}=5,0 \mathrm{mg} \mathrm{dm}^{-3} ; \mathrm{Cu}=4,6 \mathrm{mg} \mathrm{dm}^{-3} ; \mathrm{Fe}=79,2 \mathrm{mg} \mathrm{dm}^{-3}$; $\mathrm{Mn}=28,3 \mathrm{mg} \mathrm{dm}^{-3} ; \mathrm{S}=5,8 \mathrm{mg} \mathrm{dm}^{-3} ;$ Prem $=27,2 \mathrm{mg} \mathrm{L}^{-1} \mathrm{e}$ matéria orgânica $=2,4 \mathrm{dag} \mathrm{kg}^{-1}$.

Após o plantio, as mudas foram tutoradas em mourões de eucalipto perpendiculares ao solo até alcançar a altura de $1,8 \mathrm{~m}$, depois foram podadas deixando um ramo conduzido até o suporte (varas de bambu) acima dos mourões para sustentação dos cladódios.

O delineamento experimental foi em blocos casualizados, com oito adubações: testemunha, esterco de curral, cama de frango, granulado bioclástico, esterco de curral + cama de frango, esterco de curral + granulado bioclástico, cama de frango + granulado bioclástico e esterco de curral + cama de frango + granulado bioclástico, com três blocos e parcela experimental composta por quatro plantas.

As adubações foram realizadas a cada três meses, a partir de setembro de 2008 , com $14 \mathrm{~kg}$ de esterco de curral, $4 \mathrm{~kg}$ de cama de frango e $35 \mathrm{~g}$ de granulado bioclástico marinho por planta, de acordo com as combinações dos respectivos tratamentos.

As avaliações de crescimento da pitaia vermelha foram realizadas trimestralmente de setembro de 2008 a setembro de 2009. Foi avaliado o número de cladódios emitidos lateralmente abaixo do suporte e eles foram retirados com uma tesoura de poda a cada avaliação. O comprimento $(\mathrm{m})$ e o número de cladódios principais foram avaliados até os nove meses do início da adubação (momento em que alcançaram o suporte da vara de bambu). O número de cladódios emitidos acima do suporte da vara de bambu foi avaliado aos 12 meses do início da adubação, quando as plantas emitiram esses cladódios. Ao final da avaliação, foram retiradas amostras de cladódios de cada tratamento com três repetições para a análise nutricional, sendo esses cladódios lavados em água corrente, colocados para secar em estufa a $65^{\circ} \mathrm{C}$ e encaminhados para Laboratório de Análise Foliar do Departamento de Química da Universidade Federal de Lavras, MG, para avaliação dos teores de nutrientes.

Nas plantas que iniciaram a produção, foram avaliados a massa (g), o percentual de polpa, o diâmetro transversal ( $\mathrm{mm})$ e o diâmetro longitudinal $(\mathrm{mm})$ dos frutos.

Os dados foram submetidos à análise de variância e teste de Scott-Knott a 5\% de significância.

$\mathrm{Na}$ implantação do experimento, as mudas de pitaia apresentavam comprimento médio de $1,25 \mathrm{~m}$ com quatro cladódios principais e, ao final de 9 meses após o início da adubação, as mudas alcançaram o suporte de vara de bambu $(1,80 \mathrm{~m})$, com média de seis cladódios principais.

Para o número de cladódios laterais retirados das plantas de pitaia, foi observado que, a partir de seis meses do início da avaliação, houve influência do tipo de adubação. Aos 6 e 12 meses de avaliação, foi observado que a adubação composta por esterco de curral + cama de frango + granulado bioclástico proporcionou a maior emissão de brotações laterais (Tabela 1). Esse resultado pode ser atribuído ao maior valor de fósforo presente nos cladódios de pitaia (Tabela 2) devido ao granulado bioclástico interagir com a matéria orgânica, exercer uma ação corretiva da acidez do solo, promovendo melhor atividade biológica e assimilação do nutriente (DIAS, 2000).

As plantas sem adubação e apenas com aplicação de granulado bioclástico apresentaram os menores números de cladódios laterais, fato esse relacionado com menor teor de fósforo, potássio e magnésio presentes nos cladódios (Tabela 2). Esse resultado sugere que a aplicação de granulado bioclástico deve ser feita juntamente com matéria orgânica, pois a matéria orgânica, além de melhorar as propriedades químicas e físicas do solo (DAMATTO JUNIOR et al., 2006), possui nutrientes em sua composição, que são melhores disponibilizados com a 
Tabela 1 - Médias do número de cladódios laterais retirados (CLR) e número de cladódios acima do suporte (CAS) nas épocas de avaliação e massa, rendimento de polpa, diâmetro longitudinal (DL) e diâmetro transversal (DT) de frutos de pitaia vermelha em função das diferentes adubações na Universidade Federal de Lavras, MG, 2009.

\begin{tabular}{|c|c|c|c|c|c|c|}
\hline \multirow{3}{*}{ Adubações } & \multicolumn{5}{|c|}{---------------------------------CLR-------------------------------- } & \multirow{3}{*}{$\begin{array}{c}\text { CAS } \\
\text { Época (meses) } \\
12\end{array}$} \\
\hline & \multicolumn{5}{|c|}{-------------------------'Época (meses)------------------------ } & \\
\hline & 0 & 3 & 6 & 9 & 12 & \\
\hline Testemunha & $1 \mathrm{a}$ & $2 \mathrm{a}$ & $1 \mathrm{c}$ & $0 \mathrm{c}$ & $1 \mathrm{c}$ & $0 \mathrm{c}$ \\
\hline Esterco de curral (EC) & $2 \mathrm{a}$ & $5 \mathrm{a}$ & $5 \mathrm{~b}$ & $9 \mathrm{a}$ & $5 \mathrm{~b}$ & $15 \mathrm{~b}$ \\
\hline Cama de frango $(\mathrm{CF})$ & $2 \mathrm{a}$ & $3 \mathrm{a}$ & $4 \mathrm{~b}$ & $5 \mathrm{~b}$ & $4 \mathrm{~b}$ & $11 \mathrm{~b}$ \\
\hline Granulado bioclástico (GB) & $2 \mathrm{a}$ & $1 \mathrm{a}$ & $0 \mathrm{c}$ & $1 \mathrm{c}$ & $1 \mathrm{c}$ & $2 \mathrm{c}$ \\
\hline $\mathrm{EC}+\mathrm{CF}$ & $1 \mathrm{a}$ & $4 \mathrm{a}$ & $6 \mathrm{~b}$ & $7 \mathrm{~b}$ & $5 \mathrm{~b}$ & $22 \mathrm{a}$ \\
\hline $\mathrm{EC}+\mathrm{GB}$ & $2 \mathrm{a}$ & $4 \mathrm{a}$ & $5 \mathrm{~b}$ & $5 \mathrm{~b}$ & $4 \mathrm{~b}$ & $13 \mathrm{~b}$ \\
\hline $\mathrm{CF}+\mathrm{GB}$ & $2 \mathrm{a}$ & $4 \mathrm{a}$ & $3 \mathrm{~b}$ & $6 \mathrm{~b}$ & $5 \mathrm{~b}$ & $14 \mathrm{~b}$ \\
\hline $\mathrm{EC}+\mathrm{CF}+\mathrm{GB}$ & $3 \mathrm{a}$ & $5 \mathrm{a}$ & $11 \mathrm{a}$ & $10 \mathrm{a}$ & $10 \mathrm{a}$ & $18 \mathrm{a}$ \\
\hline $\mathrm{CV}_{1}(\%)$ & & & 25,0 & & & 20,5 \\
\hline $\mathrm{CV}_{2}(\%)$ & & & 10,7 & & & 24,2 \\
\hline Adubações & Massa (g) & & Polpa (\%) & & $\mathrm{DL}(\mathrm{mm})$ & DT (mm) \\
\hline Esterco curral (EC) & $190,0 \mathrm{a}$ & & $53,1 \mathrm{a}$ & & $76,0 \mathrm{a}$ & $59,0 \mathrm{a}$ \\
\hline Cama de frango (CF) & 274,0 a & & $51,2 \mathrm{a}$ & & $85,0 \mathrm{a}$ & $73,0 \mathrm{a}$ \\
\hline $\mathrm{EC}+\mathrm{CF}$ & 284,3 a & & $64,0 \mathrm{a}$ & & $88,2 \mathrm{a}$ & $75,0 \mathrm{a}$ \\
\hline $\mathrm{CF}+\mathrm{GB}$ & 214,4 a & & $59,1 \mathrm{a}$ & & $75,3 \mathrm{a}$ & $64,0 \mathrm{a}$ \\
\hline CV (\%) & 30,6 & & 6,6 & & 7,4 & 6,9 \\
\hline
\end{tabular}

Médias seguidas pela mesma letra na coluna não diferem pelo teste de Scott-Knott a 5\% de significância.

aplicação do granulado bioclástico (DIAS, 2000), favorecendo o crescimento da pitaia vermelha.

Em relação ao número de cladódios emitidos acima do suporte da vara bambu, foi observado que a adubação com esterco de curral + cama de frango com ou sem a adição de granulado bioclástico foram as mais satisfatórias (Tabela 1). Esse resultado pode ser atribuído às maiores quantidades de matéria orgânica adicionada ao solo, promovendo melhorias na infiltração, capacidade de retenção de água, drenagem, aeração, temperatura e penetração de raízes (OLIVEIRA et al., 2009).

Foi observado que as plantas adubadas com cama de frango, esterco de curral, esterco de curral + cama de frango e cama de frango + granulado bioclástico iniciaram a produção com menos de um ano

Tabela 2 - Teores $\left(\mathrm{g} \mathrm{kg}^{-1}\right)$ de nitrogênio $(\mathrm{N})$, fósforo $(\mathrm{P})$, potássio $(\mathrm{K})$, cálcio $(\mathrm{Ca})$ e magnésio $(\mathrm{Mg})$ na matéria seca dos cladódios de pitaia vermelha em função das diferentes adubações na Universidade Federal de Lavras, MG, 2009.

\begin{tabular}{llcccc}
\hline Adubações & $\mathrm{N}$ & $\mathrm{P}$ & $\mathrm{K}$ & $\mathrm{Ca}$ & $\mathrm{Mg}$ \\
\hline Testemunha & $7,5 \mathrm{a}$ & $0,8 \mathrm{c}$ & $14,6 \mathrm{~b}$ & $16,3 \mathrm{a}$ & $3,7 \mathrm{~b}$ \\
Esterco de curral (EC) & $10,4 \mathrm{a}$ & $2,0 \mathrm{~b}$ & $22,9 \mathrm{a}$ & $8,0 \mathrm{a}$ & $4,3 \mathrm{a}$ \\
Cama de frango (CF) & $10,3 \mathrm{a}$ & $2,2 \mathrm{~b}$ & $22,1 \mathrm{a}$ & $10,7 \mathrm{a}$ & $4,2 \mathrm{a}$ \\
Granulado bioclástico (GB) & $9,6 \mathrm{a}$ & $1,0 \mathrm{c}$ & $17,2 \mathrm{~b}$ & $16,8 \mathrm{a}$ & $3,4 \mathrm{~b}$ \\
EC + CF & $10,3 \mathrm{a}$ & $2,1 \mathrm{~b}$ & $23,6 \mathrm{a}$ & $10,7 \mathrm{a}$ & $4,5 \mathrm{a}$ \\
EC + GB & $9,0 \mathrm{a}$ & $1,8 \mathrm{~b}$ & $25,6 \mathrm{a}$ & $11,4 \mathrm{a}$ & $4,4 \mathrm{a}$ \\
CF + GB & $8,6 \mathrm{a}$ & $2,0 \mathrm{~b}$ & $24,4 \mathrm{a}$ & $14,9 \mathrm{a}$ & $4,3 \mathrm{a}$ \\
EC + CF + GB & $11,6 \mathrm{a}$ & $2,7 \mathrm{a}$ & $27,0 \mathrm{a}$ & $9,7 \mathrm{a}$ & $4,7 \mathrm{a}$ \\
CV(\%) & 20,7 & 16,3 & 19,7 & 34,4 & 9,5 \\
\hline
\end{tabular}

Médias seguidas pela mesma letra na coluna não diferem pelo teste de Scott-Knott a 5\% de significância.

Ciência Rural, v.41, n.5, mai, 2011. 
após plantio. No entanto, essa produção inicial não caracterizou o potencial produtivo das plantas e não foram observadas nessas plantas diferenças na massa, percentual de polpa, diâmetro transversal e longitudinal dos frutos (Tabela 1).

O início da produção das plantas desses tratamentos, logo no primeiro ano de plantio, demonstra a resposta satisfatória da pitaia vermelha à adubação orgânica, pois a aplicação de matéria orgânica ao solo melhora suas propriedades químicas e físicas (DAMATTO JUNIOR et al., 2006), disponibilizando maiores quantidades de nutrientes para as plantas.

A adubação com esterco de curral + cama de frango + granulado bioclástico favoreceu o crescimento de plantas de pitaia vermelha no campo.

\section{REFERÊNCIAS}

BASTOS, D.C. et al. Propagação de pitaya vermelha por estaquia. Ciência e Agrotecnologia, v.30, n.6, p.11061109, 2006. Disponível em: <http://www.scielo.br/ scielo.php? script $=$ sci_arttext \& pid =S 1413 $70542006000600009 \& \operatorname{lng}=p t \& n r m=i s o>$. Acesso em: 14 mar. 2010. doi: 10.1590/S1413-70542006000600009.
CRUZ, M.C.M. et al. Desenvolvimento do porta-enxerto de tangerineira Cleópatra. Revista Brasileira de Fruticultura, Jaboticabal, v.30, n.2, p.471-475, 2008. Disponível em: <http:/ $/ \mathrm{www}$.scielo.br/scielo.php?script=sci arttext\&pid $=\mathrm{S} 0100-$ $29452008000200035 \& \operatorname{lng}=\mathrm{en} \& \mathrm{nrm}=\mathrm{iso}>$. Acesso em: $10 \mathrm{mar}$. 2010. doi: $10.1590 / \mathrm{S} 0100-29452008000200035$.

DAMATTO JUNIOR et al. Alterações em propriedades de solo adubado com doses de composto orgânico sob cultivo de bananeira. Revista Brasileira de Fruticultura, Jaboticabal, v.28, n.3, p.546-549, 2006. Disponível em: <http:// www.scielo.br/scielo.php? script $=$ sci_arttext $\&$ pid $=S 0100$ $29452006000300048 \& \operatorname{lng}=e n \& n r m=i s o>$. Acesso em: 14 mar. 2010. doi: 10.1590/S0100-29452006000300048.

DIAS, G.T.M. Granulados bioclásticos - Algas calcárias. Revista Brasileira de Geofísica, São Paulo, v.18, n.13, p.307-318, 2000. Disponível em: <http://www.scielo.br/ scielo.php? script = sci_art text\&pid=S 0102 $261 \mathrm{X} 2000000300008 \& \operatorname{lng}=\mathrm{en} \& \mathrm{nrm}=\mathrm{iso}>$. Acesso em: 10 mar. 2010. doi: 10.1590/S0102-261X2000000300008.

OLIVEIRA, A.N.P. et al. Yield of gherkin in response to doses of bovine manure. Horticultura Brasileira, Brasília, v.27, n.1, p.100-102, 2009. Disponível em: <http://www.scielo.br/ scielo.php ? script = sci_arttext\&pid=S 0102 $05362009000100020 \& \operatorname{lng}=\mathrm{en} \& n \mathrm{~nm}=\mathrm{iso}>$. Acesso em: $07 \mathrm{mar}$. 2010. doi: $10.1590 / \mathrm{S} 0102-05362009000100020$. 